\title{
PRODUÇÃO DE RECURSOS EDUCACIONAIS ABERTOS PARA O DESENVOLVIMENTO DE MULTILETRAMENTOS
}

\author{
Daniervelin Renata Marques PEREIRA (D \\ Universidade Federal de Minas Gerais (UFMG) \\ Danilo Rodrigues CÉSAR (DD \\ Universidade Federal de Minas Gerais (UFMG)
}

ఠ

OPEN ACCESS

\section{EDITORES}

- Miguel Oliveira, Jr. (UFAL)

- René Almeida (UFS)

AVALIADORES

- Raimunda Belini (IFPI)

- Célia Oliveira (UFPA)

SOBRE OS AUTORES

- Daniervelin Renata Marques Pereira Conceptualização, Investigação, Escrita - Rascunho Original.

- Danilo Rodrigues César

Conceptualização, Investigação,

Escrita - Análise e Edição.

DATAS

- Recebido: 10/08/2021

- Aceito: 17/12/2021

- Publicado: 29/12/2021

\section{COMO CITAR}

PEREIRA, D.R.M.; David; CÉSAR, D.R. (2021). Produção de recursos educacionais abertos para o desenvolvimento de multiletramentos. Cadernos de Linguística, v. 2, n. 4, e481.

\section{RESUMO}

Propõe-se, a partir de uma pesquisa acadêmica realizada, abordar, no mesmo movimento da ciência e educação abertas, o histórico e conceitos de Recursos Educacionais Abertos (REA) e de multiletramentos e multimodalidade. Os REA nascem da necessidade de acesso a uma educação inclusiva, equitativa e de qualidade e os multiletramentos surgem dentro do contexto de crença de que eram necessários novos hábitos e novos valores para acompanhar as rápidas mudanças na era da Sociedade do Conhecimento, as quais demandam leitores que, em contato com textos multimodais, consigam considerar como as linguagens e culturas são mobilizadas na construção dos sentidos. A partir dessa apresentação e discussão, identifica-se uma relação produtiva entre REA e multiletramentos para estimular a produção de REA que tratem da diversidade linguística e cultural e que, licenciados abertamente, possam ser facilmente acessados, modificados e compartilhados. Com base nessa discussão conceitual, apresenta-se uma proposta de design de REA para multiletramentos, que pretende contribuir, a partir de perguntas, no percurso da construção de REA. 


\section{ABSTRACT}

Based on academic research, it is proposed to approach, in the same movement of open science and education, the history and concepts of Open Educational Resources (OER) and of multiliteracies and multimodality. OER are born from the need for access to inclusive, equitable and quality education, and multiliteracies arise within the context of the belief that new habits and new values were needed to accompany the rapid changes in the era of the Knowledge Society, which demand readers who, in contact with multimodal texts, are able to consider how languages and cultures are mobilized in the construction of meanings. From this presentation and discussion, a productive relationship between OER and multiliteracies is identified to stimulate the production of OER that address linguistic and cultural diversity and that, openly licensed, can be easily accessed, modified and shared. Based on this conceptual discussion, an OER design proposal for multiliteracies is presented, which intends to contribute, through questions, in the route of OER construction.

PALAVRAS-CHAVE

Recursos Educacionais Abertos; Multiletramentos;

Ensino-Aprendizagem.

KEYWORDS

Open Educational Resources; Multiliteracies; Teaching-Learning. 


\section{INTRODUÇÃO}

Com a expansão do acesso à internet e as novas possibilidades na cultura digital, diversos movimentos pela liberdade de usar, compartilhar e adaptar trabalhos e obras criativas têm ganhado força. Foi baseado nessa premissa que nasceu o movimento mundial dos Recursos Educacionais Abertos (REA), com a ideia simples e dificilmente questionável: o conhecimento é um bem da humanidade e deve, portanto, estar acessível a todos.

O termo "Recursos Educacionais Abertos" (REA) foi cunhado pela Organização das Nações Unidas para a Educação, a Ciência e a Cultura (UNESCO) no ano de 2002, em um fórum sobre o Impacto dos Cursos Abertos (Forum on the Impact of Open Courseware for Higher Education in Developing Countries) para discutir o fenômeno de compartilhamento aberto de recursos educacionais. Na ocasião, foram apresentadas iniciativas que demonstravam o potencial da proposta de REA para aumentar o acesso à educação inclusiva, equitativa e de qualidade. Dez anos após, em 2012, a Unesco promoveu o I Congresso Mundial de REA (World Open Educational Resources Congress) que resultou na Declaração REA de Paris, um documento construído a partir de seis fóruns realizados anteriormente em todas as regiões do mundo: Caribe, África, América Latina, Europa, Ásia e Oriente Médio, com o objetivo de ajudar governos e instituições a adotarem políticas de REA.

A UNESCO (2015) tem uma das definições mais aceitas mundialmente para REA e foi construída colaborativamente após diversos fóruns de discussão, com participação ativa da comunidade brasileira de Recursos Educacionais Abertos. Para a organização, Recursos Educacionais Abertos são:

\footnotetext{
materiais de ensino, aprendizado e pesquisa em qualquer meio disponível no domínio público, que foram disponibilizados com licenças abertas, permitindo acesso, uso, redestinação, reutilização e redistribuição por terceiros, com poucas ou sem nenhuma restrição (Atkins, Brown e Hammond, 2007)! O uso de padrões técnicos abertos melhora o acesso e o potencial de reutilização. REA podem incluir cursos/ programas completos, materiais de curso, módulos, guias do aluno, anotações de aula, livros didáticos, artigos de pesquisa, vídeos, ferramentas e instrumentos de avaliação, materiais interativos (por exemplo, simulações), dramatizações, softwares, aplicativos (incluindo para celulares) e quaisquer outros materiais úteis à educação (UNESCO, 2015, p. v).
}

No Brasil, os REA começaram a ser discutidos em 2008 com a formação de uma comunidade de pessoas de distintas áreas do conhecimento e com o Projeto REA.br Projeto Brasileiro sobre Recursos Educacionais Abertos: Desafios e Perspectivas, que teve apoio da Open Society Foundation até o ano de 2015. Tal projeto gerou uma aproximação com os gestores políticos, que passaram a formular projetos de lei de apoio aos REA, e com

1 A Review of the Open Educational Resources (OER) Movement: Achievements, Challenges, and New Opportunities (http://www.hewlett.org/uploads/files/ReviewoftheOERMovement.pdf). 
a sociedade civil, através de conscientização e formação. Um desses projetos, fruto de política pública recente, é a atualização do Projeto de Lei n 1.513/2011, aprovado dia 5 de dezembro de 2018, na Comissão de Educação da Câmara dos Deputados. "O Projeto estabelece os procedimentos a serem adotados pelo poder público na contratação, produção, subvenção e de recursos digitais, para que sejam licenciados e disponibilizados com licença aberta de direito autoral” (INICIATIVA EDUCAÇÃO ABERTA, 2018, s.p.).

Com o amadurecimento do próprio movimento e a atuação crescente da comunidade, os projetos sobre REA começaram a se multiplicar, principalmente por iniciativa das universidades públicas e pela produção de literatura específica sobre o tema. Em 2011, foi lançado o Caderno REA para professores (EDUCAÇÃO ABERTA, 2013), elaborado para professores da educação básica. Em 2012, com o apoio do Comitê Gestor da Internet, foi lançado o primeiro livro sobre REA em língua portuguesa, Recursos Educacionais Abertos: práticas colaborativas e políticas públicas (SANTANA; ROSSINI; PRETTO, 2012), composto por onze artigos e cinco entrevistas trazendo uma percepção bastante ampla do tema. Finalmente, em 2014 foi produzida a primeira vídeo-animação em língua portuguesa sobre Recursos Educacionais Abertos, resultado do projeto MIRA Mapa Interativo de Recursos Abertos -, uma parceria da Open Knowledge Brasil (OKBr), o Instituto Educadigital (IED), o Núcleo de Informática Aplicada à Educação (NIED) e a Escuela Superior Politécnica del Litoral (ESPOL).

O movimento REA comunga de muitos valores do movimento da Ciência Aberta, cujos pilares são: a transparência, a reutilização de dados de pesquisas, a reprodutibilidade de resultados e metodologias, a cooperação e a responsabilidade. Em comum, têm a busca por transparência, a reutilização de dados, a reprodutibilidade, a cooperação e a responsabilidade.

Na mesma direção, esses movimentos focam um aspecto pouco presente em pesquisas acadêmicas: o formato técnico e as licenças, que viabilizam ou não o acesso às informações inscritas nos materiais publicados. Em geral, as pesquisas linguísticas e educacionais, para ficar apenas nas áreas das quais falamos (Linguística/Linguística Aplicada e Educação), se voltam naturalmente para o conteúdo das línguas, linguagens e os textos e discursos produzidos. Raras são pesquisas e práticas nessas áreas que abordam, por exemplo, os aspectos legais, de licença e direitos autorais envolvidos na circulação de materiais didáticos no ensino superior e como isso impacta essas áreas e os conhecimentos divulgados pela comunidade acadêmica. Nosso desafio é, então, apresentar informações sobre REA, que podem também servir como orientação de como contemplar esses aspectos nas práticas dos autores de recursos educacionais, de forma que o produto disponibilizado ao público lhe dê informações sobre os limites para sua apropriação. 
Mais especificamente, este texto se propõe a abordar os REA no contexto dos multiletramentos, a partir de um percurso trilhado em uma pesquisa financiada pelo CNPq de 2014 a 2020, em que se focou a pesquisa e criação de REA para leitura e produção de textos nas licenciaturas de línguas. Um dos produtos dessa pesquisa foi a criação de uma plataforma de compartilhamento aberto de REA: http://realptl.letras.ufmg.br/realptl/. O projeto REALPTL, é importante esclarecer, em sua primeira etapa, fez uma análise discursiva de recursos educacionais diversos, para depreender suas características, e, na segunda etapa, propôs a criação de um repositório online de recursos educacionais abertos que de alguma forma promovesse atualização em relação aos materiais encontrados na primeira etapa. REA para ensino de português, espanhol e inglês compõem hoje o repositório, que é aberto a toda comunidade que tenha interesse em contribuir com a formação de professores, compartilhando seus REA. Outro objetivo deste texto é apresentar uma proposta de design de REA para multiletramentos.

Embora os REA possam ser estudados e aplicados em várias áreas de conhecimento, neste trabalho nos interessa explorar sua potencialidade na área de Letras, subárea Linguística aplicada, especificamente na perspectiva dos multiletramentos, os quais abordaremos na próxima seção.

\section{RECURSOS EDUCACIONAIS ABERTOS}

Um REA se diferencia de outros recursos basicamente por três princípios básicos: é composto por conteúdo educacional; formatos técnicos abertos e licenças abertas. Esses três princípios devem garantir que o recurso sirva aos objetivos de ensinoaprendizagem, possua uma autorização expressa do autor sobre seu uso e se apresente em um formato aberto (.odt, odp, xcf, etc.) que facilita sua circulação e modificação. Essas características são um avanço em relação ao Copyright e à Lei brasileira de Direito Autoral, uma vez que o autor já insere no recurso como outras pessoas poderão usá-lo em outros contextos e materiais.

Os três princípios citados são importantes para a concepção do recurso de aprendizagem em si, sem deixar de considerar outras práticas relacionadas ao manejo dos REA, como a construção de processos metodológicos colaborativos e as Práticas Educacionais Abertas, que garantem o uso institucionalizado de REA, incluindo atividades de apoio à criação, ao uso e ao reúso do recurso (SANTOS, 2012).

A UNESCO (2015, p. v) alerta que "o termo 'REA' não é sinônimo de aprendizado online, aprendizado na Internet, e-learning ou aprendizado móvel. Muitos REA, embora possam ser compartilhados em formato digital, estão também disponíveis para impressão". Com essa 
definição, estabelece-se mais uma abertura quanto ao formato (impresso ou digital) que os recursos podem ter, de acordo com as necessidades de sua criação e circulação.

Em relação ao conteúdo, os REA podem ser um curso completo, um plano de aula, uma sequência didática, um game, um artigo científico, uma imagem que se produziu em uma viagem, entrevistas, áudios, vídeos, a combinação de vários desses elementos, entre outras possibilidades, ficando a diversidade necessária ao processo educacional garantida.

Do ponto de vista da abertura ou formato técnico, a própria definição de REA apresentada pela UNESCO traz a recomendação preferencial pelo uso de formatos abertos que facilitem o reúso e o remix. Os formatos são abertos quando não estão vinculados a um único produto ou software e seus procedimentos para a guarda e leitura de arquivos são documentados e de acesso público. Como é necessário um software para leitura dos formatos digitais, um formato aberto permite que diversos softwares possam implementá-lo, independentemente dos direitos de propriedade. Por exemplo, se uma música possuir um formato fechado, poderá ser reproduzida apenas em softwares determinados pela empresa, o que restringe seu uso em dispositivos eletrônicos. São exemplos de formatos abertos: .odt, .odp, .ods, .odg, .txt, .png, .webm, entre outros; e de formatos fechados: $. \operatorname{doc}(\mathrm{x}), \operatorname{ppt}(\mathrm{x}), \mathrm{xls}(\mathrm{x})$, entre outros proprietários.

A abertura legal garante o direito autoral e, ao mesmo tempo, garante liberdades mínimas que são definidas pelo autor da obra e podem gerar novos usos, novos recursos didáticos e novas ideias. A ideia principal dos REA, então, é que eles podem ser utilizados e recombinados por outras pessoas, aumentando o conhecimento de todos. Assim, torna-se possível que o recurso possa conectar pessoas, em locais e modos diferentes, para satisfazer uma necessidade específica de conhecimento.

Considerando que os REA nada mais são que materiais que visam apoiar o processo de aprendizagem, a diferença desses materiais para os que tipicamente encontramos gratuitamente (sob diferentes designações, como material didático, recurso digital ou outra) são as licenças de uso, as quais são flexíveis e dão ao autor o poder de escolher de que modo outras pessoas poderão usar esse material, e a abertura técnica, ou seja, adoção de formatos que sejam fáceis de abrir e modificar em qualquer software. Destacamos o trabalho de Pereira, Fettermann e César (2016) que analisa discursivamente um diálogo em rede social para definição de REA. Eles mostram que, em um extremo, caracterizado como menos aberto, são colocados os recursos educacionais, distribuídos na internet, mas que não permitem modificações e nem uso comercial. Citam-se outros recursos educacionais mais abertos, que permitem derivações, mas não uso comercial. No outro extremo do contínuo, os recursos são essencialmente abertos, pois permitem uso, aprimoramento, recombinação e distribuição, desde que citada a autoria.

Dessa forma, apenas disponibilizar gratuitamente um recurso educacional na Internet, por exemplo, não o caracteriza como um Recurso Educacional Aberto, porque, para se 
caracterizar como REA, algumas liberdades mínimas devem ser concedidas ao usuário final pelo autor da obra. Para o pesquisador Wiley (2015, s.p.), essas liberdades são conhecidas como os 5Rs:

- Reusar: compreende a liberdade de usar o original em distintos contextos;

- Revisar: compreende a liberdade de adaptar e melhorar o REA para que se ajustem às suas necessidades;

- Recombinar: compreende a liberdade de combinar e fazer misturas e colagens de um REA com outros REA originando novos materiais;

- Redistribuir: compreende a liberdade de compartilhar o REA original e a versão alterada;

- Reter: compreende a liberdade de fazer cópia e guardar o recurso em qualquer dispositivo pessoal.

A licença Creative Commons (https://creativecommons.org/) é mais adotada para garantir um tipo de licença aberta, sendo possível ao autor escolher no site o tipo que melhor atende seus objetivos na orientação ao outro sobre o que pode ser feito com sua criação. A seguir, pela Figura 1, apresentamos um exemplo de uso da licença Creative Commons mais aberta (CC BY) no livro Recursos Educacionais Abertos: práticas colaborativas e políticas públicas, o que mostra que, além de abordar o assunto, o próprio livro é um REA, e mostra ainda sua aceitação também por editoras.

Esta obra está sob a licença Creative Commons Atribuição 2.5 (CC-BY). Mais detalhes em http://creativecommons.org/licenses/by/2.5/br

(c) (i) Você pode copiar, distribuir, transmitir e remixar este livro, ou partes dele, desde que cite a fonte.

Coordenaçāo editorial: Maracá - Educação e Tecnologias | Casa da Cultura Digital Capa, projeto gráfico e diagramaçāo: Lucas Pretti Revisāo: Daniela Silva, Thiago Carrapatoso e Flávia Rosa Assistência administrativa: Viviane Souza

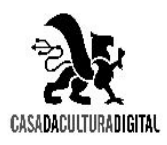

Casa da Cultura Digital

Maracá Educação e Tecnologias Rua Vitorino Carmilo, 459 Santa Cecilia - São Paulo - SP (11) 3662-0571 casadaculturadigital.com.br

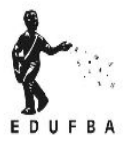

Editora da Univeridade Federal da Bahia

Rua Barão de Jeremoabo, s/n Campus de Ondina - Salvador - BA

(71) 3283-6164

www.edufba.ufba.br

edufba@ufba.br

Figura 1. Licença Creative Commons utilizada na obra Recursos Educacionais Abertos: práticas colaborativas e políticas públicas. Fonte: Ficha catalográfica do livro (SANTANA; ROSSINI; PRETTO, 2012). 
Um benefício da adoção de REA na educação é driblar o alto custo dos livros didáticos, distribuídos nas escolas básicas e pagos pelo poder público. Além disso, vai na contramão da restrição em relação a sua reprodução, já que seu conteúdo está vinculado ao selo "Todos os direitos reservados", como destacam Rossini e Gonzalez (2012). Isso quer dizer que não pode ser aproveitado ou adaptado segundo as necessidades do cotidiano da sala de aula, limitando, por sua vez, a forma como o conhecimento se constrói.

A utilização de licenças pode ocorrer, então, pelo site Creative Commons (https://creativecommons.org/choose/?lang=pt), respondendo-se a algumas perguntas, selecionando-se a licença apropriada para o material elaborado e seguindo as instruções para incluir o código HTML ou copiar o texto para inclusão em outro formato de material.

Antes de mostrarmos como articulamos os REA aos multiletramentos, na próxima seção nos ocuparemos de definir este último conceito.

\section{OS MULTILETRAMENTOS}

O conceito de multiletramentos remete à noção anterior de letramento(s). "Letramento" é um termo que surgiu por volta da década de 1970-80 e no início foi muito confundido com "alfabetização". No singular, "letramento" é criticado por remeter a um só tipo de letramento, geralmente o ensino canônico da língua e da literatura, o valorizado pela escola e instâncias sociais que têm mais voz. Enquanto o letramento designa o desenvolvimento de habilidades de uso do sistema de escrita em práticas sociais (SOARES, 2017), a alfabetização se restringe ao sentido de "levar à aquisição do alfabeto', ou seja, ensinar o código da língua escrita, ensinar as habilidades de ler e escrever" (SOARES, 2017, 16). Alfabetização é, então, localizada no domínio inicial e letramento é um processo contínuo. Mais tarde, o uso mais corrente passa a ser no plural, "letramentos", contemplando a diversidade de práticas possíveis de uso social da leitura e da escrita: entrevistas, uso de caixa eletrônico, atendimento telefônico, venda de ambulantes e muitas outras práticas existentes e que possam ser criadas. Essas práticas não envolvem só a letra; por consequência, letramentos podem envolver números e outros signos. Podemos desenvolver, por exemplo, a leitura de mapas, que é uma prática de letramento possível.

Atualmente, o termo evolui para outras formas: multiletramentos e novos letramentos. Dessa forma, destaca-se que a ideia dos multiletramentos nasce dentro do contexto de crença de que eram necessários novos hábitos e novos valores para acompanhar as rápidas mudanças na era da Sociedade do Conhecimento, no cenário de grandes desenvolvimentos tecnológicos. A motivação do termo é a multiplicidade de canais de comunicação e a grande diversidade cultural e linguística. Bill Cope e Mary Kalantzis, da University of Illinois Urbana-Champaign, contam, em um texto de 2013, que o Grupo de Nova 
Londres (New London Group), formado pelos pesquisadores Cazden, Cope, Fairclough, Gee, Kalantzis, Kress, Luke, Michael, Nakata e Bianco, cunhou o termo multiletramentos em meados dos anos 1990, o que se materializou em um artigo-manifesto de 1996 e, em seguida, em um texto publicado em 2000, intitulado "Multiliteracies: Literacy Learning and the Design of Social Futures".

Nesses textos iniciais, o Grupo de Nova Londres explica que a Pedagogia dos Multiletramentos pretende retirar a tradicional ênfase no letramento alfabético, que precisa ser suplementado pela aprendizagem da leitura e da escrita de textos multimodais que integram outros modos de linguagem (visual, gestual, espacial, além do linguístico), já que eles são crescentemente integrados nas mídias e práticas culturais contemporâneas (COPE; KALANTZIS, 2009).

Por isso, podemos dizer que a noção de multiletramentos é mais ampla que a própria língua, dependendo de modos de representação de uma cultura e contexto. O conceito contempla um grande volume de textos que nos rodeiam no dia a dia, materializados em várias linguagens (verbal, não verbal e mista), responsáveis por organizações discursivas que orientam nossas práticas sociais. Nessa perspectiva, tomamos "texto" no seu sentido amplo, podendo ser uma carta, um outdoor, um podcast, um filme ou mesmo uma aula gravada.

Como esclarece Rojo e Moura (2012), letramentos (múltiplos) apontam para a multiplicidade e variedade das práticas letradas, valorizadas ou não, nas sociedades em geral. Já o conceito de multiletramentos aponta para dois tipos específicos e importantes de multiplicidade presentes em nossas sociedades, principalmente urbanas, na contemporaneidade: a multiplicidade cultural das populações (incluindo a diversidade linguística das comunidades) e a multiplicidade semiótica de constituição dos textos por meio dos quais ela se forma e se comunica.

Segundo García-Canclini (2008 apud ROJO; MOURA, 2012, p. 13), o que "hoje vemos à nossa volta são produções culturais letradas em efetiva circulação social, como um conjunto de textos híbridos de diferentes letramentos (vernaculares e dominantes), de diferentes campos (ditos "popular/de massa/erudito")". Nesse sentido, segundo esse autor, não se pode fazer divisões tradicionais, como culto/inculto, cultura erudita/popular e central/marginal. Vivemos, como alerta Rojo e Moura (2012), pelo menos desde o início do século XX (senão desde sempre), em sociedades de híbridos impuros, fronteiriços, ou seja, de textos, práticas e culturas que se definem justamente pela mescla, pela relação com outros textos, práticas e culturas.

Na perspectiva de García-Canclini (2008), de descolecionar os "monumentos" patrimoniais escolares, pela introdução de novos e outros gêneros de discurso - ditos por Canclini “impuros" -, de outras e novas mídias, tecnologias, línguas, variedades, linguagens,

são requeridas uma nova ética e novas estéticas. Uma nova ética que já não se baseia tanto na propriedade (de direitos de autor, de rendimentos que se dissolveram na navegação livre da WEB), mas no diálogo (chancelado, citado) entre novos interpretantes (os remixers, 
mashupers). Uma nova ética que, seja na recepção, seja na produção ou design, baseia-se nos letramentos críticos [...], isto é, carece de critérios de análise crítica (ROJO; MOURA, 2012, p. 16, grifos no original).

Podemos analisar por esse trecho que a proposta de REA, no que diz respeito à ruptura da ideia de direitos autorais fechados e do recurso autoral como inalterável, está em convergência nesse sentido com o movimento dos multiletramentos, inseridos numa hipermodernidade que tem no horizonte a mescla, a mistura e a fusão, em prol da colaboratividade e dos benefícios que ela pode gerar. É preciso ressaltar, entretanto, que os REA não estão originalmente na proposta dos multiletramentos, e vice-versa, embora pensemos que pode ser produtivo criar REA para multiletramentos, como defendemos neste artigo.

Cope e Kalantzis (2009) perceberam que os meios de comunicação estão cada vez mais reconfigurando o modo como usamos a linguagem, que vem se tornando, como reflexo desse processo, multimodal. Por multimodalidade podemos entender a combinação de diferentes modos semióticos (também chamados de linguagens ou expressões) na construção do artefato ou evento comunicativo (VIEIRA; SILVESTRE, 2015).

Houve um tempo em que usávamos basicamente a linguagem verbal (oral e escrita) nas comunicações, mas ao lado dela hoje contamos com formas visuais, audiovisuais e formas em movimento, por exemplo. Além do letramento para a comunicação verbal, é preciso acrescentar a aprendizagem dos designs multimodais dos textos. Isso se organiza num quadro de diversidade local e da conectividade global, pois, ao mesmo tempo em que valorizamos nossa cultura local, o que nos diferencia, abrimo-nos ao que vem de fora, que aflora nessas várias linguagens pelas mídias sociais, cada vez mais numerosas.

Nas Figuras 2 e 3 a seguir, de licença aberta, podemos comparar como os textos mudaram ao longo dos anos em sua organização multimodal:

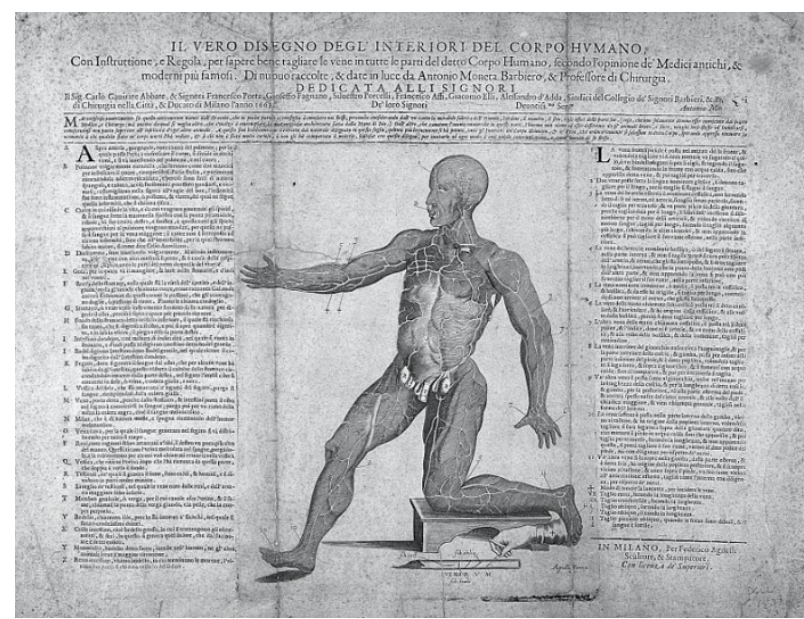

Figura 2. MONETA, Antonio Moneta, II Vero Disegno Degl' Interiori Del Corpo Humano, after 1663. Photographic reproduction of Moneta's manuscripts of the interior of the human body with flap down. Fonte: https://commons.wikimedia.org/wiki/File:MONETA;_II_Vero_Disegno_Degl\%27_Interiori_Wellcome_L0031964.jpg 


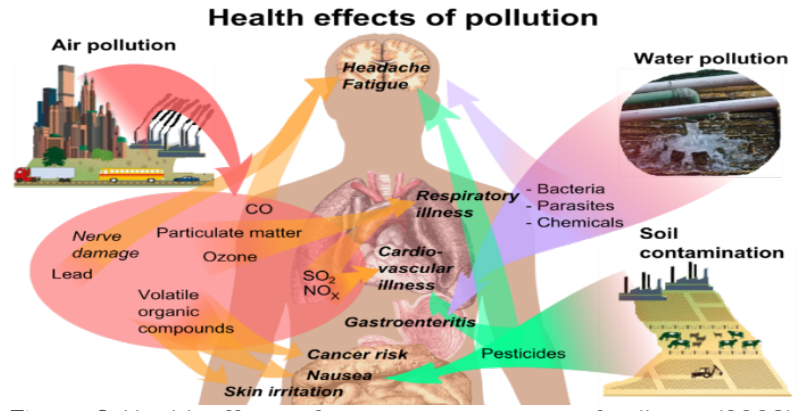

Figura 3. Health effects of some common types of pollution (2009).

Fonte: https://commons.wikimedia.org/wiki/Human_body_diagrams\#/media/File:Health_effects_of_pollution.png

Como podemos ver, o texto da Figura 2 é monocromático, com excesso de texto verbal em tamanho de fonte pequena e sem espaçamento que facilite sua leitura. Trata-se de um texto publicado em 1663 que circulou em formato impresso. A Figura 3 mostra um exemplo de texto digital de 2009 com uma nova forma de organização, em que os modos semióticos (recursos da imagem e da escrita), tornam o texto menos linear, já que o olhar do leitor não é orientado numa só direção. Poderíamos citar ainda exemplos de vídeos que abordam o mesmo assunto, corpo humano, que trariam exemplos de outros recursos, como áudio e movimento. Esses textos estão mais próprios aos novos modos de aprendizagem, tornando necessário o desenvolvimento de multiletramentos para sua apreensão.

Os multiletramentos concebem, assim, o conhecimento como imerso em contextos sociais, culturais e materiais, afetado pelas interações com os outros. Cope e Kalantzis (2000; 2009) e Kalantzis e Cope (2005) propõem, a partir dessa concepção, a Pedagogia dos Multiletramentos, pensada na perspectiva de que a mente humana é incorporada, situada e social.

Essa Pedagogia parte de instrução explícita e prática situada, incluindo o enquadramento crítico e a prática transformada, que culminaria na aplicação de um conhecimento aprendido em uma situação típica, mas, além disso, envolveria também uma aplicação de forma inovadora ou em uma situação diferente. Nessa perspectiva, foi proposto um modelo de multiletramentos em 2000 e, em 2005, ele foi reformulado, como pode ser visto no Quadro 1: 


\begin{tabular}{|c|c|c|c|}
\hline \multicolumn{2}{|c|}{$\begin{array}{l}\text { Modelo de Multiletramentos } \\
\text { (COPE; KALANTZIS, 2000) }\end{array}$} & \multicolumn{2}{|c|}{$\begin{array}{l}\text { Aprendizagem por design } \\
\text { (KALANTZIS; COPE, 2005) }\end{array}$} \\
\hline $\begin{array}{l}\text { Situated Practice } \\
\text { (Prática Situada) }\end{array}$ & $\begin{array}{l}\text { aquisição por meio de } \\
\text { práticas significativas } \\
\text { dentro de uma } \\
\text { comunidade } \\
\text { aprendizes que é capaz } \\
\text { de ocupar múltiplos e } \\
\text { diferentes papéis } \\
\text { baseados em suas } \\
\text { origens e experiências. }\end{array}$ & $\begin{array}{l}\text { Experiencing } \\
\text { (Experimentação) }\end{array}$ & $\begin{array}{l}\text { parte-se sempre do } \\
\text { conhecido, do } \\
\text { conhecimento pessoal, } \\
\text { que é evidência da vida } \\
\text { diária do aprendiz, } \\
\text { tendo em vista que o } \\
\text { conhecimento humano } \\
\text { é situado } \\
\text { contextualizado. }\end{array}$ \\
\hline $\begin{array}{l}\text { Overt Instruction } \\
\text { (Instrução Explícita) }\end{array}$ & $\begin{array}{l}\text { intervenções ativas para } \\
\text { fundamentar atividades } \\
\text { de aprendizagem; não } \\
\text { implicar transmissão } \\
\text { direta, repetições, } \\
\text { memorizações, embora } \\
\text { tenha essas conotações. }\end{array}$ & $\begin{array}{l}\text { Conceptualizing } \\
\text { (Conceitualização) }\end{array}$ & $\begin{array}{l}\text { envolve definir } \text { e } \\
\text { aplicar conceitos. É a } \\
\text { partir da junção de } \\
\text { diversos conceitos que } \\
\text { o conhecimento da } \\
\text { disciplina é construído } \\
\text { como um todo. }\end{array}$ \\
\hline $\begin{array}{l}\text { Critical Framing } \\
\text { (Enquadramento } \\
\text { Crítico) }\end{array}$ & $\begin{array}{l}\text { crescente domínio na } \\
\text { prática, controle e } \\
\text { compreensão consciente } \\
\text { das relações históricas, } \\
\text { sociais, culturais, } \\
\text { políticas e ideológicas } \\
\text { centradas no valor de } \\
\text { determinados sistemas } \\
\text { de conhecimento e } \\
\text { prática social. }\end{array}$ & Analysing (Análise) & $\begin{array}{l}\text { relação de causa e } \\
\text { efeito e da razão de ser } \\
\text { das coisas. É o } \\
\text { momento em que se } \\
\text { evidenciam } \\
\text { objetivos, motivos, } \\
\text { intenções e pontos de } \\
\text { vista das pessoas. }\end{array}$ \\
\hline $\begin{array}{l}\text { Transformed Practice } \\
\text { (Prática } \\
\text { Transformada) }\end{array}$ & $\begin{array}{l}\text { os estudantes devem } \\
\text { demonstrar como podem } \\
\text { criar e cumprir de } \\
\text { maneira refletida novas } \\
\text { práticas fundadas em } \\
\text { seus próprios objetivos e } \\
\text { valores. }\end{array}$ & Applying (Aplicação) & $\begin{array}{l}\text { Aplicação } \\
\text { conhecimento } \\
\text { mundo "real", em uma } \\
\text { situação típica e ampla } \\
\text { no sentido de que, } \\
\text { criativamente, } \\
\text { conhecimento } \\
\text { aplicado de forma } \\
\text { inovadora } \\
\text { transferido para uma } \\
\text { situação diferente. }\end{array}$ \\
\hline
\end{tabular}

Quadro 1. Modelos de multiletramentos. Fonte: Baseado em: Silva (2016).

A partir dessa dimensão mais geral, é possível já afirmar que desenvolver uma Pedagogia dos Multiletramentos é não só tarefa da educação básica ou das licenciaturas, mas deve estar presente em qualquer prática educacional, formal ou não-formal, tendo em vista as multimodalidades e o multiculturalismo presentes em nossas sociedades.

Cope e Kalantzis (2005) definem cultura como "a soma total do que nós aprendemos no contexto em que nos tornamos pessoas que aprendem" e conhecimento como "o processo de conectar as coisas da mente com as coisas do mundo" (KALANTZIS; COPE, 2005, p. 70), mas também influenciado pelas emoções dos sujeitos (ibid.). Nessa perspectiva, a aprendizagem acontece na relação entre aquele que constrói o conhecimento e aquilo que se pode conhecer, em que o aprendiz descobre que pode realmente aprender e avaliar como válido.

Segundo Rojo e Moura (2012), são necessárias novas ferramentas além das tradicionais de escrita manual e impressa. É necessário que saibamos não só ler, mas desvendar com certa profundidade os sentidos inscritos na produção e circulação de áudios, vídeos, imagens e mesmo os textos essencialmente verbais escritos. Novas práticas 
emergem do uso social das atuais e das tecnologias contemporâneas, o que demanda abertura para os necessários multiletramentos.

\section{LEITURA DE TEXTOS MULTIMODAIS}

A multiplicidade de linguagens ou modos presentes nos textos atualmente é chamada de multimodalidade ou multissemiose. Rojo e Moura (2012, p. 23) destacam algumas características importantes dos textos nos multiletramentos:

\footnotetext{
(a) eles são interativos; mais que isso, colaborativos;

(b) eles fraturam e transgridem as relações de poder estabelecidas, em especial as relações de propriedade (das máquinas, das ferramentas, das ideias, dos textos [verbais ou não]);

(c) eles são híbridos, fronteiriços, mestiços (de linguagens, modos, mídias e culturas).
}

Com a cada vez mais frequente materialização dos textos em mídias digitais, o formato de redes (hipertextos, hipermídias) é um traço que compõe os textos dos gêneros digitais, próprios dessa esfera de circulação, e que também caracterizam essa multimodalidade.

Importante destacar que um texto multimodal usa diferentes linguagens ou expressões para construir um só significado. Por isso, não podemos dizer que a linguagem verbal de uma tirinha, por exemplo, produz um sentido e a visual, outro; ou que os significados são a soma do que cada parte poderia significar separadamente. Elas se integram na construção de uma totalidade semântica, mesmo que cada uma contribua de formas diferentes.

Concordamos com Vieira (2015, p. 44) quando afirma que "se, em essência, os textos são multimodais, será impossível ler significados representados apenas por um modo linguístico". Foi também nossa constatação ao refletir sobre o tratamento do gênero filme na sala de aula (PEREIRA; SOUSA, 2017). As autoras apontam um problema que ocorre quando, por exemplo, ao se tratar da Grécia Antiga, sugere-se que os alunos vejam o filme Tróia (2004), de Wolfgang Petersen, porém, sem nenhuma problematização do próprio filme e da forma como se constrói. No trabalho com o texto cinematográfico é importante, além do conteúdo, observar a performance (a construção do personagem e os diálogos), a linguagem da montagem e dos planos e a composição cênica (figurino, cenário, trilha sonora e fotografia). Sem um trabalho com as várias linguagens e suas articulações em um texto multimodal como esse, deixamos escapar o objeto e seu sentido.

Cope e Kalantzis (2009) definem assim as modalidades:

- Linguagem escrita: escrita (representação do significado para o outro) e leitura (representação do significado para si mesmo) - escrita a mão, página impressa, tela;

- Linguagem oral: fala gravada ou ao vivo (representação do significado para o outro); escuta (representação do significado para si mesmo);

- Representação visual: imagem parada ou em movimento, escultura, artesanato (representação do significado para o outro); visão, vista, cena, perspectiva (representação do significado para si mesmo); 
- Representação auditiva: música, sons ambientes, barulhos, alertas (representação do significado para o outro); ouvir, escutar (representação do significado para si mesmo);

- Representação tátil: toque, cheiro e sabor: representação para si de sensações corporais e sentimentos ou representações para os outros que "tocam" um corpo. Formas de representação tátil incluem cinestesia, contato físico, sensações da pele (temperatura, textura, pressão), apreensão, objetos manipuláveis, artefatos, cozinhar e comer, aromas;

- Representação gestual: movimentos das mãos e braços, expressões da face, movimentos dos olhos e o olhar, traços do corpo, marcha, roupa e moda, penteado, dança, sequências de ação (Scollon, 2001), cronometragem, frequência, cerimônia e ritual. Aqui, gesto é entendido de forma ampla e metaforicamente mais como um ato físico de assinatura (como em "um gesto para...") do que o significado literal mais restrito do movimento das mãos e dos braços.

- A representação para si pode assumir a forma de sentimentos e emoções ou ensaiar sequências de ação no olho da mente.

- Representação espacial: proximidade, espaçamento, disposição, distância interpessoal, territorialidade, arquitetura/construção, paisagem urbana, panorama. (COPE; KALANTZIS, 2009, p. 178-179, tradução nossa ${ }^{2}$.

Os autores destacam, ao abordar a questão das multimodalidades, que a linguagem escrita continua fortemente presente nas práticas de linguagem. Segundo eles, ela está apenas se tornando mais intimamente interligada com os outros modos e, em alguns aspectos, tornando-se mais parecida com eles (COPE; KALANTZIS, 2009).

Há várias perspectivas de abordagem e propostas de análise de textos visuais. Essa análise se torna cada vez mais necessária no contexto da forte presença da cultura visual, baseada na multiplicidade de recursos semióticos utilizados e na rapidez da conexão visual. Kress e van Leeuwen (1996), por exemplo, propuseram uma gramática do visual, na obra Reading images: the grammar of visual design. Dessa obra são apresentadas categorias para a análise e a leitura de imagens. Por exemplo: a informação nova colocada geralmente à direita, e a velha, à esquerda; saliente e não saliente; acima e abaixo, estabelecem valores significativos no ato de leitura de imagens em uma perspectiva multimodal. A semiótica francesa concebe o texto como constituído

2. "Written language: writing (representing meaning to another) and reading (representing meaning to oneself)handwriting, the printed page, the screen

- Oral language: live or recorded speech (representing meaning to another); listening (representing meaning to oneself)

- Visual representation: still or moving image, sculpture, craft (representing meaning to another); view, vista, scene, perspective (representing meaning to oneself)

- Audio representation: music, ambient sounds, noises, alerts (representing meaning to another); hearing, listening (representing meaning to oneself)

- Tactile representation: touch, smell and taste: the representation to oneself of bodily sensations and feelings or representations to others that "touch" one bodily. Forms of tactile representation include kinaesthesia, physical contact, skin sensations (temperature, texture, pressure), grasp, manipulable objects, artefacts, cooking and eating, aromas

- Gestural representation: movements of the hands and arms, expressions of the face, eye movements and gaze, demeanours of the body, gait, clothing and fashion, hairstyle, dance, action sequences (Scollon, 2001), timing, frequency, ceremony and ritual. Here gesture is understood broadly and metaphorically as a physical act of si ning (as in "a gesture to ...") rather than the narrower literal meaning of hand and arm movement

- Representation to oneself may take the form of feelings and emotions or rehearsing action sequences in one's mind's eye

- Spatial representation: proximity, spacing, layout, interpersonal distance, territoriality, architecture/building, streetscape, cityscape, landscape." 
de um plano do conteúdo e um plano da expressão, que são analisados separadamente, mas entendendo o texto como uma totalidade de sentido. Para a análise da expressão, há um conjunto de obras que propõem metodologia de análise, como Pietroforte (2004) e Oliveira e Teixeira (2009). Para essa perspectiva teórica, uma expressão plástica pode ser analisada em categorias cromáticas, eidéticas e topológicas, de forma articulada com a análise do percurso gerativo de sentido.

Segundo Vieira (2015), no discurso multimodal a modalização realiza-se pela:

1. combinação das cores entre si,

2. pelos usos de tons claros e escuros,

3. pela escolha de sombra e luz,

4. pelo uso de alto e baixo relevo,

5. pela escolha do modelo de tipografia, de iconografia, ou modo de combinação, ou arranjo.

A autora (2015, p. 49) ainda cita os estudos de Kress e van Leeuwen na construção de uma gramática do design visual, em que apresentam as escalas: de detalhes, de plano de frente e de fundo, de dimensionalidade (quantas?), de sombra e luz (quais são os contornos dos objetos quanto ao uso da sombra e da luz?), de matizes (há gradação? Há muitas cores?), de intensidade de cores (são opacas ou intensas, frias ou quentes?), de brilho (que tipo de informação merece o uso de uma cor brilhante ou fosca?), de cores puras ou híbridas (as cores representam crenças e ideologias? O que motiva suas escolhas e combinações?), de quantidade de cores (monocromáticas ou policromáticas?), de luminosidade (pendem para o claro ou para o escuro?), de elementos tipográficos (por que certas informações estão em caixa alta e outras em baixa? Qual a razão para que algumas delas sejam veiculadas em fontes extremamente grandes e outras em fontes pequenas?).

Portanto, o tipo e tamanho de letra, o papel, como o ambiente online é configurado (onde aparecem os menus, se tem mais ou menos informações escritas, imagens etc.), tudo isso influencia a leitura e a produção de sentidos pelo leitor. O alinhamento justificado, por exemplo, em textos científicos é estabelecido como um hábito no meio acadêmico e escrever de outra forma pode interferir na credibilidade do leitor. Já o design na escrita de uma carta é bem mais livre que na escrita do artigo ou de um ofício de intimação judicial. Assim, sabemos que as escolhas estão associadas ao uso de um gênero discursivo, de uma esfera de atividade.

Como exemplo de texto que surge no contexto das multimodalidades, podemos citar os recursos criativos empregados pelo restaurante Maria das Tranças, em Minas Gerais, ao criar um cartão publicitário que é entregue aos clientes (Figuras 4 e 5 e Gif). O efeito humorístico do cartão é gerado pela sequência de imagens construídas pela dobradura do papel. A primeira imagem, com o cartão fechado, visto na primeira página, pode lembrar 
as nádegas de alguém sentado (verbalmente, apresenta-se o aviso "Não seja malicioso!") e, ao abrir o cartão (pela esperada curiosidade que a imagem inicial e aviso verbal geraram), rompe-se com o efeito malicioso pela apresentação de uma imagem ingênua (de um frango, logomarca do estabelecimento) na terceira página do cartão. Os efeitos malicioso e humorístico do cartão são alcançados pela forma de construção do suporte material do cartão impresso (que tem um corte em círculo na primeira página para mostrar apenas parte da imagem integral do frango na terceira página) e a distribuição espacial de suas partes. Para facilitar a visualização, criamos o Gif para mostrar o movimento previsto na leitura do texto (na primeira imagem o cartão está fechado e na segunda, aberto).

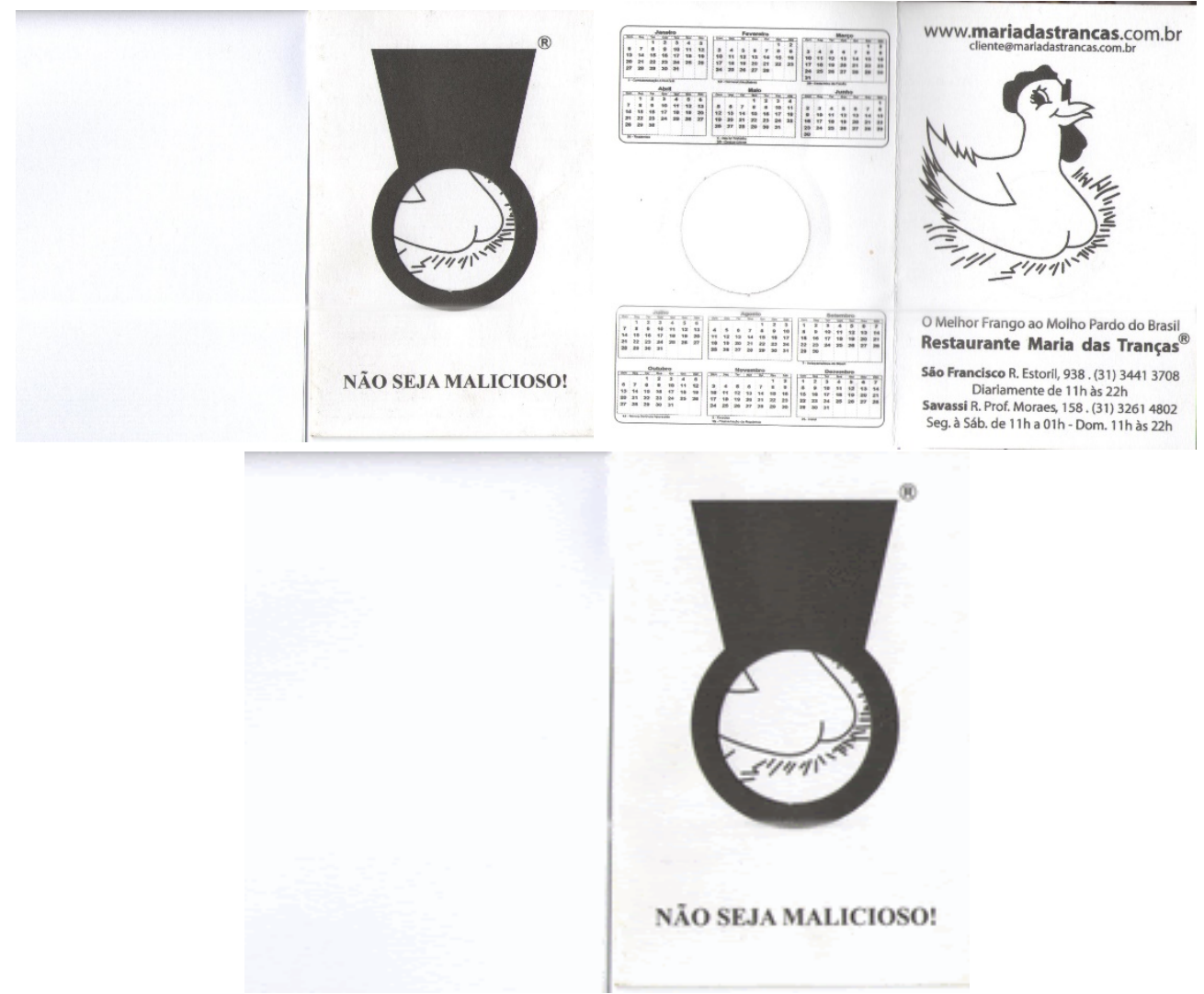

Figuras 4 e 5. Partes do cartão publicitário do restaurante Maria das Tranças, de Belo Horizonte-MG. Gif das Figuras 4 e 5. Fonte: Maria das Tranças. Gif gerado por Daniervelin Pereira no programa http://picasion.com/. Disponível em: https://i.picasion.com/pic91/b6ea52e1c2b0d6e028ccc5e7ea35798f.gif. Acesso em: 15 jun. 2021.

O trabalho didático com esse texto pode, assim, explorar os percursos de análise de um texto multimodal, buscando desenvolver os multiletramentos pelo estudo dos recursos expressivos das imagens (cor e forma, distribuição planejada do espaço, relação partetodo) e a configuração do texto verbal (enunciado inicial com texto do tipo injuntivo, finalizado com ponto de exclamação, uso de negrito e tamanhos diferentes de fonte, apresentação de calendário e endereço do restaurante) e seus efeitos de sentido, 
alcançados pela articulação entre esses elementos. Além disso, não se pode desconsiderar, para entendimento desse texto multimodal, seu pertencimento a um gênero (cartão) e esfera (publicitária e culinária), e por seu suporte material em dobradura de papel (que comporta, inclusive, o gênero calendário). Pode-se, ainda, estimular que os estudantes, em uma atividade didática para aplicarem e desenvolverem os conhecimentos, usem a criatividade para produzir um cartão que explore recursos visuais e verbais para divulgar algum evento da comunidade escolar, por exemplo.

\section{REA E MULTILETRAMENTOS}

Os sentidos da palavra "multiletramentos" - da diversidade cultural de produção e circulação dos textos e/ou no sentido da diversidade de linguagens que os constituem podem favorecer a interatividade e colaboratividade dos Recursos Educacionais Abertos (REA). Parece-nos empobrecedor e restritivo pensar em um REA que se limitaria a propagar uma cultura valorizada e que use apenas uma linguagem (a escrita formal, por exemplo). Pela própria noção de abertura dos REA, cria-se uma expectativa em relação a nossas ações enquanto sujeitos usuários (não receptores passivos ou espectadores), inseridos no contexto de hipertextos e hipermídias, que permite interação em vários níveis, incluindo o papel de autor.

Nesse sentido, criar REA em diferentes linguagens, com hipertextos, contemplando diferentes culturas, pode estabelecer um diálogo produtivo com o cenário em que educadores e aprendizes se inserem em práticas formais e não-formais de ensino-aprendizagem.

Os REA não precisam ser sobre língua para ensinar leitura e escrita, para trabalhar multiletramentos, já que estes permeiam toda nossa prática social. Há, por exemplo, REA com infográficos de várias áreas do conhecimento, que pretendem ajudar nas capacidades de: navegar-localizar, relacionar-avaliar e compreender-usar, como propõe Paiva (2016, p. 48-49), na leitura de impressos e materiais online.

Apresentamos a seguir, embasados nas discussões sobre REA, multiletramentos e multimodalidades, promovidas neste artigo, uma proposta de design de REA com perguntas orientadoras que não pretendem fechar o que deve ser feito, mas estimular reflexões que podem servir de guia ou de revisão do REA criado (ver Figura 6). A proposta foi pensada para orientar os criadores de REA.

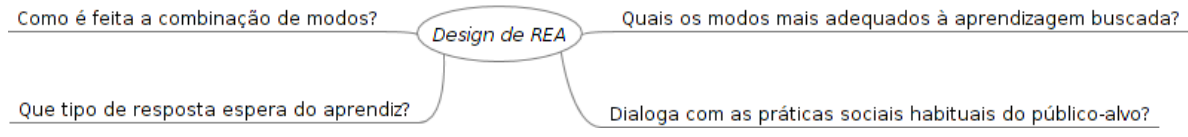

Figura 6: diagrama de design de REA. Fonte: autoria própria. 
Nesse diagrama, temos algumas questões que podem ajudar na construção de REA para multiletramentos. Algumas questões servem para explicitar os tópicos caros à pedagogia dos multiletramentos e deixar mais claros os elementos mobilizados na proposta; outras servem também como "check-list", para o autor do REA refletir se o tópico foi considerado no material. Comentamos cada questão a seguir, de forma a esclarecer a proposta:

\subsection{QUAIS OS MODOS MAIS ADEQUADOS À APRENDIZAGEM BUSCADA?}

Alguns aprendizes podem se sentir mais confortáveis com um modo de linguagem do que com outro (fazemos aqui referência à teoria das inteligências múltiplas, de Gardner (2000)). Alguns preferem, a partir de uma leitura, fazer listas de tópicos, outros preferem criar fluxogramas ou mapas conceituais, por exemplo. De acordo com Cope e Kalantzis (2009), podemos fazer muitas coisas semelhantes em diferentes modos. Se uma prática educacional restringir o aprendizado a um modo apenas (como costuma fazer com o verbal), segregado dos demais, favorecerá alguns tipos de aprendizes em detrimento de outros. Apresentar diferentes modos, não só os que são mais confortáveis para o autor do REA e o público-alvo, pode ser uma maneira de ampliar o repertório representacional dele. Além disso, há uma complementaridade que pode ser estabelecida entre os modos: se as palavras não fizerem sentido por si sós, o diagrama pode, e então as palavras começam a fazer sentido. Ainda é preciso lembrar que cada modo contempla determinados sentidos: as palavras, as imagens e os sons fazem sentido em um contexto e cada uma dessas linguagens estabelece modos de leitura que dependem, sempre, de se considerar a totalidade do texto multimodal e os efeitos de o uso de cada uma promovem para o sentido geral. Segundo Cope e Kalantzis (2009, p. 181, tradução nossa3): "A troca de modo consciente contribui para um aprendizado mais poderoso".

Ao escolher linguagem escrita e/ou visual e/ou sonora, por exemplo, é preciso ter em mente, segundo Cope e Kalantzis (2009), que ler e ver requerem diferentes tipos de imaginação e esforço transformacional na representação de seus significados. "São formas fundamentalmente diferentes de conhecer e aprender o mundo" (ibid., p. 180, tradução nossa ${ }^{4}$.

3 "Conscious mode switching makes for more powerful learning."

4 "They are fundamentally different ways of knowing and learning the world". 


\subsection{COMO É FEITA A COMBINAÇÃO DOS MODOS SEMIÓTICOS?}

Naturalmente, costumamos perceber os textos em sua totalidade, de forma holística, mesmo que nos detenhamos em um determinado modo ou linguagem específicos em um momento. Cope e Kalantzis (2009) destacam que alguns modos estão tradicionalmente associados: gestos podem vir com som; imagens e texto costumam aparecer juntos nas páginas; espaços arquitetônicos são marcados com sinais escritos. De acordo com os autores, "Grande parte da nossa experiência representacional cotidiana é intrinsecamente multimodal” (COPE; KALANTZIS, 2009, p. 179, tradução nossa5). Além disso, alguns modos são frequentemente combinados: a linguagem escrita está intimamente ligada ao visual no uso de espaçamento, layout e tipografia; a linguagem falada está intimamente associada ao modo de áudio no uso de entonação, inflexão, tom, andamento e pausa, com ainda alertam os autores. Dessa forma, é preciso atentar para essa combinação, mais ou menos natural, e suas implicações para aquele que vai se deparar com a totalidade do texto. Combinações inesperadas também podem ser relevantes na produção de alguns sentidos. O importante é ter em mente como é feita a combinação e efeitos de sentido possíveis, em diálogo com as outras perspectivas do design dos REA.

\subsection{O REA DIALOGA COM AS PRÁTICAS SOCIAIS HABITUAIS DO PÚBLICO-ALVO?}

Há algumas décadas, pela perspectiva educacional de letramento que se tinha, não era tão claro que nossa aprendizagem acompanha as tendências de desenvolvimento das mídias, atreladas às mudanças sociais e culturais em processo. Hoje, em tempos de grande acesso às várias mídias, com a expansão do acesso à internet, principalmente, não temos como escapar do contato com memes, vídeos diversos, tirinhas e outros vários textos multimodais. E saber ler criticamente esses textos é uma nova competência que devemos desenvolver. Do contrário, a escola falará uma "língua" que os estudantes não entendem ou entendem, mas não lhes atrai, além de fazer pouco sentido para sua rotina de leitura diária.

Cope e Kalantzis (2009, p. 172) lembram que estamos no meio de uma profunda mudança cultural, na qual, como trabalhadores, cidadãos e pessoas, somos cada vez mais obrigados a ser usuários, jogadores, criadores e consumidores exigentes, em vez de espectadores, delegados, audiências ou consumidores quiescentes de uma modernidade anterior. Gee (2004) alerta que, enquanto as escolas se detêm no ensino de letras e sons às crianças, elas já rapidamente dominam um complexo sistema de signos, como encontram em videogames, sem a ajuda do professor.

5 "Much of our everyday representational experience is intrinsically multimodal." 
Dessa forma, é preciso ter em mente que o aprendiz pode estar em meio a essas transformações e participar de práticas sociais que estão irremediavelmente constituídas de várias linguagens que ele deve saber ler e responder de forma crítica. Ao criar REA, é necessário, assim, ter clareza sobre as práticas sociais que o público-alvo (cada vez menos homogêneo) precisa dominar. Essa concepção dialoga em alguma medida com a pedagogia de Paulo Freire, segundo a qual o educador precisa necessariamente considerar a realidade dos educandos em suas práticas pedagógicas.

\subsection{QUE TIPO DE RESPOSTA ESPERA DO APRENDIZ?}

REA podem ser quaisquer tipos de materiais educacionais, como definimos anteriormente. O tipo de material produzido, além de como é produzido, pressupõe um tipo de resposta esperada. Exercícios com perguntas, com feedback automático ou não, exigem uma tentativa do aprendiz; uma sequência didática cria a expectativa de um percurso de atividades sobre um tema e, geralmente, produção textual no final; fotografias esperam informar, inspirar os destinatários. Quando escolhemos o tipo de REA e o desenhamos, já criamos um tipo de resposta esperada, mesmo que não seja explicitada no mesmo ambiente de compartilhamento do REA. Essa escolha deve ser feita com base na dinâmica que se pretende, no público-alvo (professor ou aluno), no conteúdo e na sua abordagem, entre outros aspectos que surgem no processo de construção.

Assim, quando falante/ouvinte e produtor/leitor são vistos como sujeitos sociais, circunscritos à história, cultura e, mesmo, às tecnologias, o contexto passa a ter um lugar de destaque nesse processo de construção de sentidos e construção também do conhecimento. E nesse processo, são essenciais, dentre outros, elementos como: subjetividade, pessoalidade, unicidade que caracterizam os contextos de interação dos sujeitos na construção do conhecimento.

Com essa proposta de design de REA, que deve, para concretizar suas características, ter uma licença aberta (alguma das licenças Creative Commons, por exemplo) e ter formato que favoreça facilidade de uso e modificações, pretendemos contribuir para a construção de REA que tenham como objetivo o desenvolvimento de multiletramentos, sendo possível e desejável sua reelaboração e complementação em futuras pesquisas e práticas pedagógicas, além da adaptação ao público em foco. Neste site, é possível encontrar um exemplo de REA que partiu dessa proposta de design de REA e surgiu no contexto da pesquisa que mencionamos na introdução: http://realptl.letras.ufmg.br/realptl/arquivos/1970. 


\section{CONSIDERAÇÕES FINAIS}

Neste artigo, buscamos discutir a construção de REA para multiletramentos a partir da apresentação dos conceitos de REA, multiletramentos e multimodalidades. Desse percurso, surgiu uma proposta para orientar o design de REA a partir de perguntas orientadoras que têm em vista incitar, principalmente, professores a desenvolverem recursos abertos, além de se apropriarem dos já disponíveis.

A articulação entre esses conceitos é um caminho possível que tem como meta formar sujeitos multiletrados, que estejam de alguma forma preparados para serem protagonistas, fundamentalmente, nas práticas sociais das quais participa, no mundo do trabalho, na vida pública e nos modos de vida pessoal (COPE; KALANTZIS, 2009).

Salientamos que os REA podem ser produzidos fora da proposta de multiletramentos e que os conceitos não são originalmente associados, mas acreditamos que essa associação abre possibilidades de uso em diferentes áreas de conhecimento, podendo ser configurados em diversos tipos de recursos, para diferentes públicos em qualquer nível de ensino.

Destacamos, ainda, que o modelo de design ou construção de REA apresentado nesse texto pode ser aperfeiçoado em outras pesquisas e, pensando-se em seus possíveis produtos (REA criados), abre-se, ainda, a possibilidade de, pela licença aberta, compartilhamentos e adaptações que, de forma contínua, podem contribuir para a esperada educação inclusiva, equitativa e de qualidade.

\section{AGRADECIMENTOS}

Deixamos, por fim, nosso agradecimento à equipe desenvolvedora do curso de extensão Educação Aberta e Recursos Educacionais Abertos, financiado pela Capes em 2018. Foi no trabalho coletivo, na perspectiva da ciência e educação aberta, que, com Tel Amiel, Priscila Gonsales, Débora Sebriam, Miguel Said Oliveira, Henrique Oliveira da Silva, Tiago Soares e Daniel Pinheiro, pudemos melhor compreender a iniciativa aberta e multiplicar, assim, o que construímos naquela oportunidade.

\section{REFERÊNCIAS}


COPE, Bill; KALANTZIS, Mary. (Eds.) Multiliteracies. Literacy Learning and the Design of Social Futures. Routlege: London, 2000.

COPE, Bill; KALANTZIS, Mary. "Multiliteracies": New Literacies, New Learning, Pedagogies: An International Journal, v. 4, n. 3, p. 164-195, 2009. DOI: 10.1080/15544800903076044.

GARDNER, Howard. Inteligências Múltiplas: a teoria na prática. Porto Alegre: Artes Médicas, 2000.

GEE, James Paul. Situated language and learning. a critique os traditional schooling. London: Routledge. 2004.

KALANTZIS, Mary; COPE, Bill. Learning by Design Project Group. Learning by Design, Victorian Schools Innovation Commission \& Common Ground, Melbourne, 2005.

INICIATIVA EDUCAÇÃO ABERTA. Projeto de Lei REA aprovado na Comissão de Educação. Publicado em: 07 de dezembro de 2018. Disponível em: https://aberta.org.br/projeto-de-lei-rea-aprovado-na-comissao-de-educacao/. Acesso em: 10 jun. 2021.

NEW LONDON GROUP. A pedagogy of multiliteracies: designing social futures. Harvard Educational Review, 66, p. 60-92, 1996.

MIRA - Mapa Interativo de Recursos Abertos. Disponível em:

https://www.youtube.com/watch?v=MTrUZfTwy_c\&t=1s. Acesso em: 10 jun. 2021.

SANTANA, Bianca; ROSSINI; PRETTO, Nelson De Lucca (org.). Recursos Educacionais Abertos: práticas colaborativas políticas públicas. Salvador: Edufba; São Paulo: Casa da Cultura Digital, 2012.

OLIVEIRA, Ana Claudia de; TEIXEIRA, Lucia (org.). Linguagens na comunicação: desenvolvimentos de semiótica sincrética. São Paulo: Estação das Letras e Cores, 2009.

PAIVA, Francis Arthuso. Leitura de imagens em infográficos. In: COSCARELLI, Carla Viana (Org.). Tecnologias para aprender. São Paulo: Parábola, 2016, p. 43-59.

PEREIRA, Daniervelin Renata Marques; FETTERMANN, Joyce; CÉSAR, Danilo Rodrigues. O que são recursos educacionais abertos? Limites e possibilidades em discursos. Calidoscópio, v. 14, n. 3, p. 458-465, set/dez 2016. DOI: 10.4013/cld.2016.143.09. Disponível em:

http://revistas.unisinos.br/index.php/calidoscopio/article/view/cld.2016.143.09. Acesso em: 18 jun. 20121.

PEREIRA, Daniervelin Renata Marques; SOUSA, Vanda Maria. O cinema na escola: recurso pedagógico e experiência sensível. In: Thalma Panerai; Ana Beatriz Gomes de Carvalho. (Org.). Mídias digitais e mediações interculturais. Recife: Amazon, 2017, p. 329-401.

PIETROFORTE, Antonio Vicente. Semiótica visual. São Paulo: Contexto, 2004.

PROJETO REA BR. Disponível em: http://www.rea.net.br/. Acesso em: 10 jun. 2019.

REALPTL. Recursos Educacionais Abertos para Leitura e Produção de Textos nas Licenciaturas. Disponível em: http://realptl.letras.ufmg.br/realptl/. Acesso em: 15 jun. 2021.

ROJO, Roxane; MOURA, Eduardo (Orgs.). Multiletramentos na escola. São Paulo: Parábola, 2012.

ROSSINI, Carolina; GONZALEZ, Cristiana. REA: o debate em política pública e as oportunidades para o mercado. In: SANTANA, Bianca; ROSSINI, Carolina; PRETTO, Nelson De Lucca (org.). Recursos Educacionais Abertos: práticas colaborativas políticas públicas. Salvador/Edufba, São Paulo/Casa da Cultura. Digital, 2012. p. 35-69.

SANTOS, Andreia Inamorato dos. Educação Aberta: histórico, prática e o contexto dos recursos educacionais abertos. In: SANTANA, Bianca; ROSSINI, Caroline; PRETTO, Nelson De Luca (Org.). Recursos Educacionais Abertos: práticas colaborativas e políticas públicas. São Paulo: Casa da Cultura Digital, 2012. p. 71-90.

SILVA, Themis Rondão Barbosa da Costa. Pedagogia dos multiletramentos: principais proposições metodológicas e pesquisas no âmbito nacional. Letras, Santa Maria, v. 26, n. 52, p. 11-23, jan./jun. 2016. DOI: 10.5902/2176148525319. Disponível em: https://periodicos.ufsm.br/letras/article/view/25319. Acesso em: 18 jun. 2021.

SOARES, Magda. Alfabetização e letramento. 7. ed. São Paulo. Contexto, 2017. 
UNESCO. Forum on the Impact of Open Courseware for Higher Education in Developing Countries, UNESCO, Paris, 1-3 July 2002. Disponível em: https://unesdoc.unesco.org/ark:/48223/pf0000128515. Acesso em: 15 jun. 2021.

UNESCO. Diretrizes para Recursos Educacionais Abertos (REA) no Ensino Superior. Paris, FR: UNESCO, 2015. Disponível em: http://unesdoc.unesco.org/images/0021/002136/213605e.pdf. Acesso em: 10 jun. 2021.

UNESCO. World Open Educational Resources Congress. 2012. Disponível em:

http://www.unesco.org/new/en/communication-and-information/events/calendar-of-events/eventswebsites/World-Open-Educational-Resources-Congress. Acesso em: 10 jun. 2021.

VIEIRA, Josenia; SILVESTRE, Carminda. Introdução à multimodalidade contribuições da gramática sistêmicofuncional análise de discurso crítica semiótica social. Brasília, DF: J. Antunes Vieira, 2015.

VIEIRA, Josenia. A multimodalidade nos eventos de letramento. In: VIEIRA, Josenia; SILVESTRE, Carminda. Introdução à multimodalidade contribuições da gramática sistêmico-funcional análise de discurso crítica semiótica social. Brasília, DF: J. Antunes Vieira, 2015, p. 43-72. Disponível em:

http://www.cepadic.com/pdf/livro_multimodalidade.pdf. Acesso em: 25 jul. 2018

WILEY, David. The Access Compromise and the 5th R. 2015. Disponivel em: https://opencontent.org/blog/archives/3221. Acesso em: 15 jun. 2021. 